\title{
Recorregut de recerca geològica i mineralògica per la comarca del Matarranya i la Terra Alta: des de Vall-de-Roures a Fondespatla
}

Josep Maria Mata-Perelló

Andrés Pocoví Juan

Joaquim Sanz Balagué

Jaume Vilaltella

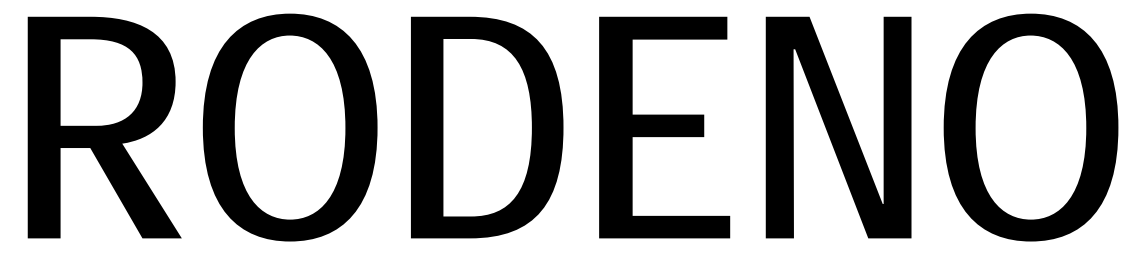

\section{REVISTA DE GEOLOGÍA ARAGONESA}

\section{n. 3}

SEPTIEMBRE 2015 


\title{
RECORREGUT DE RECERCA GEOLÒGICA I MINERALÒGICA PER LA COMARCA DEL MATARRANYA LA TERRA ALTA: DES DE VALL-DE- ROURES A FONDES
}

\author{
Josep Maria Mata-Perelló \\ Museu de geologia Valentí Masachs, Escola Politècnica Superior d'Enginyeria de Manresa \\ (EPSEM), Universitat Politècnica de Catalunya · BarcelonaTech (UPC), 08272 Manresa, Spain
}

\author{
Andrés Pocovi Juan \\ Universidad de Zaragoza, Departamento de Ciencias de la Tierra ( DCT- UZ) \\ Joaquim Sanz Balagué \\ Departament d'Enginyeria Minera i Recursos Naturals (EMRN), Escola Politècnica Superior \\ d'Enginyeria de Manresa (EPSEM), Universitat Politècnica de Catalunya - BarcelonaTech \\ (UPC), 08272 Manresa, Spain
}

\section{Jaume Vilaltella Farràs.}

Sociedad Española para la Defensa del Patrimonio Geológico y Minero (SEDPGYM)

Palabras clave: patrimonio minero; patrimonio geológico

\section{Resum}

Recorregut realitzat el 17 de novembre de 2013. En aquesta ocasió, el recorregut del present itinerari discorrerà per una zona en la qual conflueixen tres unitats geològiques netament diferenciades: la Depressió Geològica de I'Ebre, la Serralada Prelitoral Catalana (del Sistema Mediterrani), i la Serralada Ibèrica.

Així, cap els voltants de Beseit ho farà per la tercera unitat, a la denominada Zona d'Enllaç, prop ja del Sistema Ibèric. Cal dir que circularem més lluny de la zona corresponent a la segona unitat (la Serralada Prelitoral Catalana del Sistema Mediterrani).

Per d'altra banda, en diferents trams del recorregut, circularem per la primera titat (la Depressió Geològica de l'Ebre).

També cal dir d'altra banda, que el recorregut de l'itinerari discorrerà per una sola comarca, la del Matarranya, situant-se sempre dintre de la Regió de Tortosa. 


\section{ADVERTIMENTS PREVIS}

Com en altres recorreguts de RECERCA GEOLÒGICA I MINERALÒGICA ..., si es disposa del temps suficient, poden efectuar-se passant per totes les parades i filloles. En cas contrari, recomanem prescindir de les anomenades PARADES - CONDICIONALS.

També recomanem de cercar la informació més adient, sobre els trams a recórrer mitjançant camins de terra, o de pista. Precisament, en aquest itinerari, hi ha alguns trajectes d'aproximació cap a les mines, que haurem de fer per camins de terra en irregular estat de conservació. Aquest és cas de l'accés a les Mines de bauxita de Picosa.

Per d'altra banda, recomanem tenir una cura extrema de la NATURA, evitant qualsevol forma d'agressió sobre ella, o de fer-n'hi un mal ús del que en ofereix la nostra mare Terra.

\section{OBJECTIUS FONAMENTALS D’AQUEST ITINERARI}

Els objectius fonamentals que es pretenen aconseguir en aquest itinerari, es poden concretar en els següents aspectes generals:

1.- Observació i descripció dels materials terciaris (de l’Eocè i de l’Oligocè) de la Depressió Geològica de l'Ebre, que pertanyen majoritàriament al complex al·luvial de Gandesa - Horta de Sant Joan, que inclou, entre altres a la Formació Montsant i a la Formació Flix. Aquests materials, els anirem trobant a diferents indrets del recorregut de l'itinerari, pels termes de Vall-de-roures i Fondespatla. Cal dir que bona part d'aquesta zona, s'inclou dintre del denominat Avant-país, situat al contacte entre la Depressió Geològica de l’Ebre i la Serralada Ibèrica.

2.- Observació i descripció dels materials mesozoics (del Triàsic, del Juràssic i del Cretàcic) i dels cenozoics (de l'Eocè i de l'Oligocè), que constitueixen la Serralada Prelitoral Catalana,. Aquests materials els trobarem a diferents indrets del recorregut de l'itinerari.

3.- Observació de les estructures locals d'aquestes unitats geològiques acabades d'esmentar, que trobarem al llarg del recorregut de l'itinerari, i de les relacions existents entre elles. Així:

3A) de l'estructura de la Depressió Geològica de l'Ebre, que veurem als primers i als darrers trams del recorregut.

3B) de l'estructura de Branca Externa de la Serralada Prelitoral Catalana (integrant del Sistema Mediterrani), que trobarem a diferents trams del recorregut. En molts indrets, aquests es troben prop de la seva Zona d'Enllaç amb el Sistema Ibèric.

3C) de les relacions existents entre les unitats i sotsunitats geològiques acabades d'esmentar. 
4.- Observació i reconeixement de diferents mineralitzacions situades a diferents indrets del recorregut de l'itinerari, (però sempre dintre de les dues branques de la Serralada Prelitoral Catalana), com són les mineralitzacions bauxitíferes de rebliment de cavitats d'origen càrstic, situades a Fondespatla (Matarranya), entre altres indrets, localitzant-se entre els afloraments carbonatats del Juràssic.

5.- Observació de les antigues explotacions mineres relacionades amb les mineralitzacions anteriors. Al respecte, cal dir que totes elles es troben actualment aturades.

6.- Observació i anàlisi dels impactes produïts sobre el Medi Natural (i sobre el Medi Ambient), tant per les explotacions mineres anteriors, com per altres activitats humanes.

7.- Observació dels diferents indrets relacionats amb el Patrimoni Geològic i Miner, que trobarem al llarg del recorregut. Dintre d'aquest context, cal parlar de les mineralitzacions de rebliment de cavitats kàrstiques i també de les restes del Forn de Calç, que trobarem a Picosa.

\section{ANTECEDENTS BIBLIOGRÀFICS}

Pel que fa al recorregut del present itinerari, existeixen alguns antecedents molt propers, obra del mateix autor del present itinerari. Es tracta de MATA-PERELLÓ (1996b, 1997, 2000a, 2000b, 2001a, 2001b i 2011). Un altre antecedent parcial, obra del mateix autor, es troba a MATA-PERELLÓ (1989), i correspon a un altre itinerari.

Pel que fa a la descripció de les mineralitzacions d'aquesta comarca, farem esment d'un altre treball del mateix autor, de MATA-PERELLÓ (1991), relatiu a les mineralitzacions catalanes en general. Uns altres antecedents, cal situar-los en MATAPERELLÓ (1995a, 1995b, 2005a y 2005b), relatius als inventaris mineralògics de les comarques de la Terra Alta i del Matarranya.

I, finalment, pel que fa a l'estructura geològica de la zona per la qual discorre l'itinerari, farem esment dels treballs de GUIMERÀ et altri (1982) i de RIBA et altri (1976). També, i dintre d'aquest apartat, també farem esment de diversos treballs de l'IGME (1972). Tots ells són relatius a diversos fulls geològics corresponents als indrets per on passarà el recorregut de l'itinerari.

Tots aquests treballs referenciats, i d'altres, figuren esmentats per ordre alfabètic a l'apartat dedicat a la BIBLIOGRAFIA.

\section{RECORREGUT DE L'ITINERARI}


El recorregut de l'itinerari començarà al poble de Vall-de-Roures. Després, el recorregut es dirigirà cap a la veïna població de Fondespatla, per on es faran diverses aturades. La primera una mica abans del poble, a l'entorn d'unes antigues explotacions de bauxita.

Posteriorment, el recorregut arribaria finalment a l'Ermita de Sant Miquel, de Fontespatlla, on es realitzaria la darrera parada del recorregut de l'itinerari, que aquí finalitzaria definitivament.

\section{DESCRIPCIÓ DE L'ITINERARI}

Com de costum, estructurarem el recorregut de l'itinerari en una sèrie de PARADES, que tot seguit anirem veient. En cada una d'aquestes aturades farem un breu comentari (geològic o mineralògic, segons s'escaigui). Cada una d'aquestes parades tindrà un número, i un topònim representatiu. Per d'altra banda, s'indicarà el nom del poble més proper, el municipi al qual pertany l'indret, i la comarca on es troba situat. Per d'altra banda, també indicarem en cada cas, i entre parèntesi, el full topogràfic on es troba l'aturada.

Finalment, cal dir que el recorregut de l'itinerari s'inclourà dintre dels següents fulls, del "Mapa Topográfico Nacional", realitzats a l'escala 1:50.000 per l'"Instituto Geográfico y Catastral": 520 (dit de Pena-roja de Tastavins) i 521 (dit de Beseit.).

Així doncs, la relació de parades ordenades, que composen aquest itinerari geològic i mineralògic, és el següent:

PARADA 1. CARRETERA A FONTDESPATLLA, DES DE VALL-DEROURES (A-1221), IMMEDIACIONS DEL Km 15, (terme municipal de Fondespatla, comarca del Matarranya). (Full 521).

Tot i que el recorregut l'haurem iniciat a la població de Vall-de-roures (la capital comarcal), ens caldrà sortir cap a ponent per la carretera autonòmica A-1221. A uns 4 Km abans d'arribar a Fondespatla, ens caldrà fer una nova aturada. Així haurem recorregut uns $15 \mathrm{Km}$, des de l'inici del recorregut.

En aquest recorregut, es van tallant els nivells terciaris, de la Depressió Geològica de l'Ebre, els quals es troben constituïts per nivells de calcolutites i gresos cenozoics. Aquests són els materials que apareixen a l’indret de l’aturada.

Així, aquí ens trobem ara amb uns materials cenozoics del Grup del GuadalopeCastellote, els quals es troben molt verticalitzats, tot forma part de la zona de l'Avant-país 
plegat. Així, en aquest lloc es troba un contacte d'aquests materials, molt verticalitzats a la carretera. I gairebé subhoritzontals al NW de la mateixa, però prop d'ella. Així es pot veure una clara discordança progressiva, en molt poca extensió de terreny. FOTOGRAFIA 1.

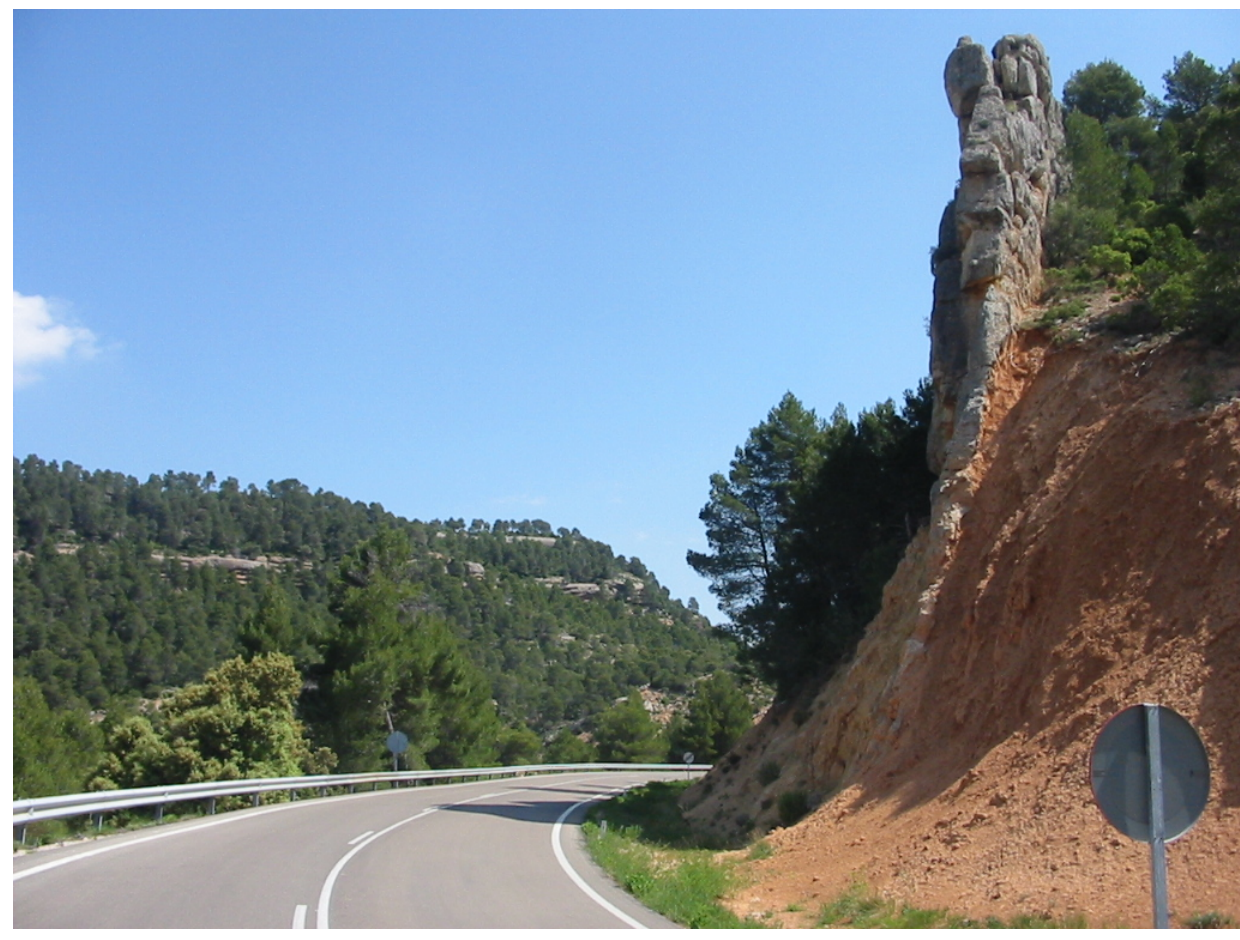

FOTOGRAFIA 1 (PARADA 1)

La discordança progressiva de la carretera a Fondespatla

\section{PARADA 2 - CONDICIONAL. FON DE CALÇ DEL CAMÍ A LA PICOSA, (terme municipal de Fondespatla, comarca del Matarranya). (Full 521).}

Des de la parada anterior, cal continuar cap a Fondespatla. A uns 3'5 Km abans d'arribar al darrer poble i a uns $0^{\prime} 3 \mathrm{Km}$ de recorregut, trobarem un camí ascendent per l'esquerra que on hi ha un antic forn de calç. En aquest indret farem, si s'escau, una nova aturada.

En aquest recorregut, haurem trobat afloraments dels materials esmentats a l'aturada anterior, els quals pertanyen al cenozoic de la Depressió Geològica de l'Ebre. On ens trobem ara situats entre afloraments d'aquests materials, sovint recoberts per terrenys detrítics quaternaris.

En aquest indret hi havia un antic Forn de Calç, el qual es troba en un lamentable estat de conservació. Per al seu funcionament, utilitzava els fragments carbonatats dels derrubis de pendent. FOTOGRAFÍA 4. 


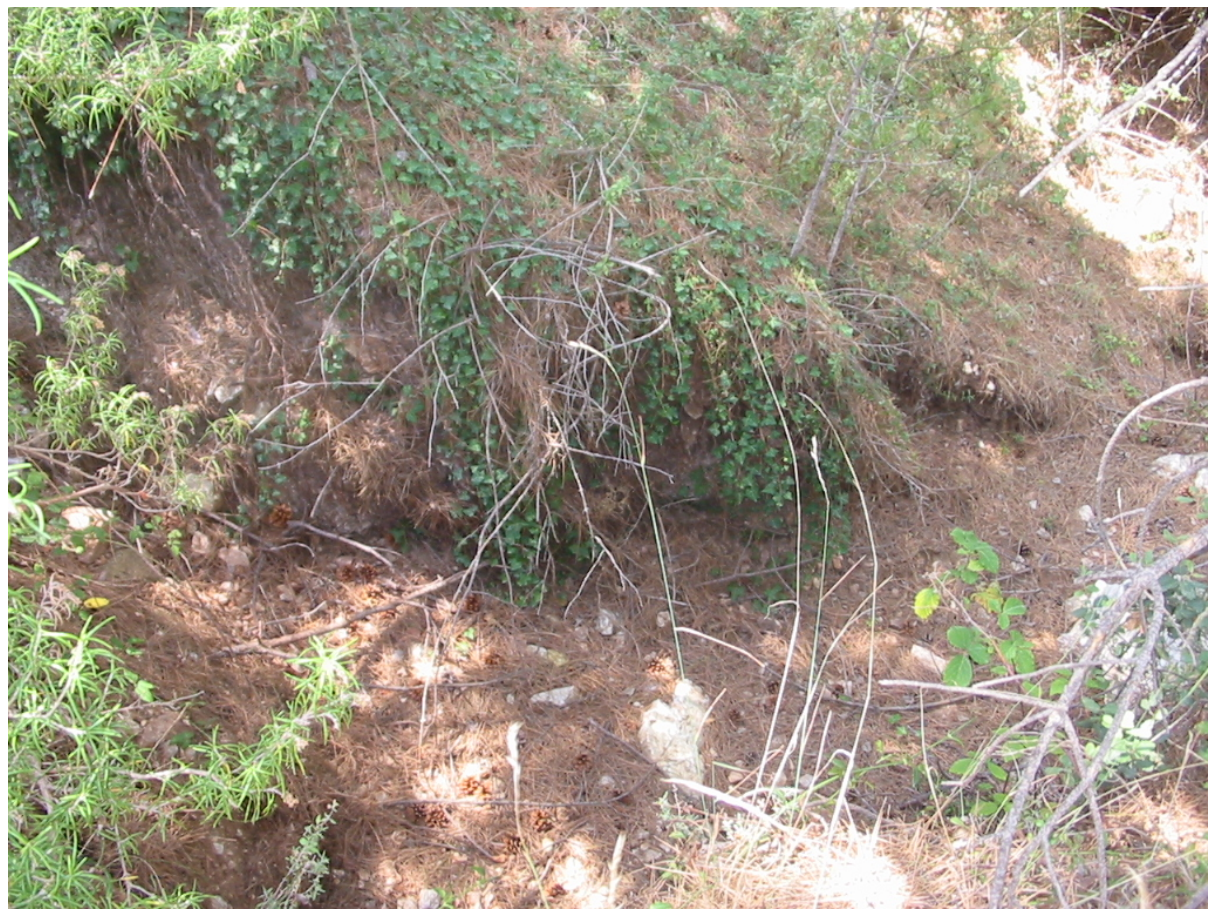

FOTOGRAFIA 2 (PARADA 2)

Restes molt malmesos de l'antic forn de calç

PARADA 3. LA PICOSA, (terme municipal de Fondespatla, comarca del Matarranya). (Full 521).

Des de la parada anterior, cal continuar per camí ascendent. Aquest camí condueix cap a l'indret de la Picosa, on va haver-hi unes antigues explotacions de BAUXITA. En aquest indret, farem la present aturada, després de recórrer uns altres $1^{\prime} 5 \mathrm{Km}$, des de la parada anterior.

En aquest recorregut, des del forn de calç, fins a les antigues explotacions de bauxita, es torna a penetrar de nou a la làmina d'encavalcament de l'Embassament de la Pena, tallant-se afloraments calcaris dels nivells mesozoics del Juràssic i del Cretàcic.

A l'indret de l'aturada, sobre els materials calcaris del Juràssic, hi ha unes mineralitzacions bauxitíferes de rebliment de cavitats d'origen càrstic. El rebliment es troba format per òxids, hidròxids i silicats d'alumini; i per òxids i hidròxids de ferro. Pel que fa als minerals d'alumini, entre els primers (els oxids i hidròxids), que formen les BAUXITES, es troben: ALUMOGEL, BOEHMITA, DIASPOR i GIBBSITA.. I entre els silicats d'alumini, es troba fonamentalment la CAOLINITA. Al mateix temps entre els òxids i hidròxids de Fe es troben la GOETHITA (que apareix en forma de LIMONITA), i l'HEMATITES. També es troben altres minerals com la CALCITA; així com PIROLUSITA (dendrítica). FOTOGRAFIA 3 
Per d'altra banda, des d'aquest indret, es pot gaudir, mirant cap al Nord, i cap al NW, d'uns bonics exemples de relleus tabulars, desenvolupats entre els materials terciaris de l'Oligocè.

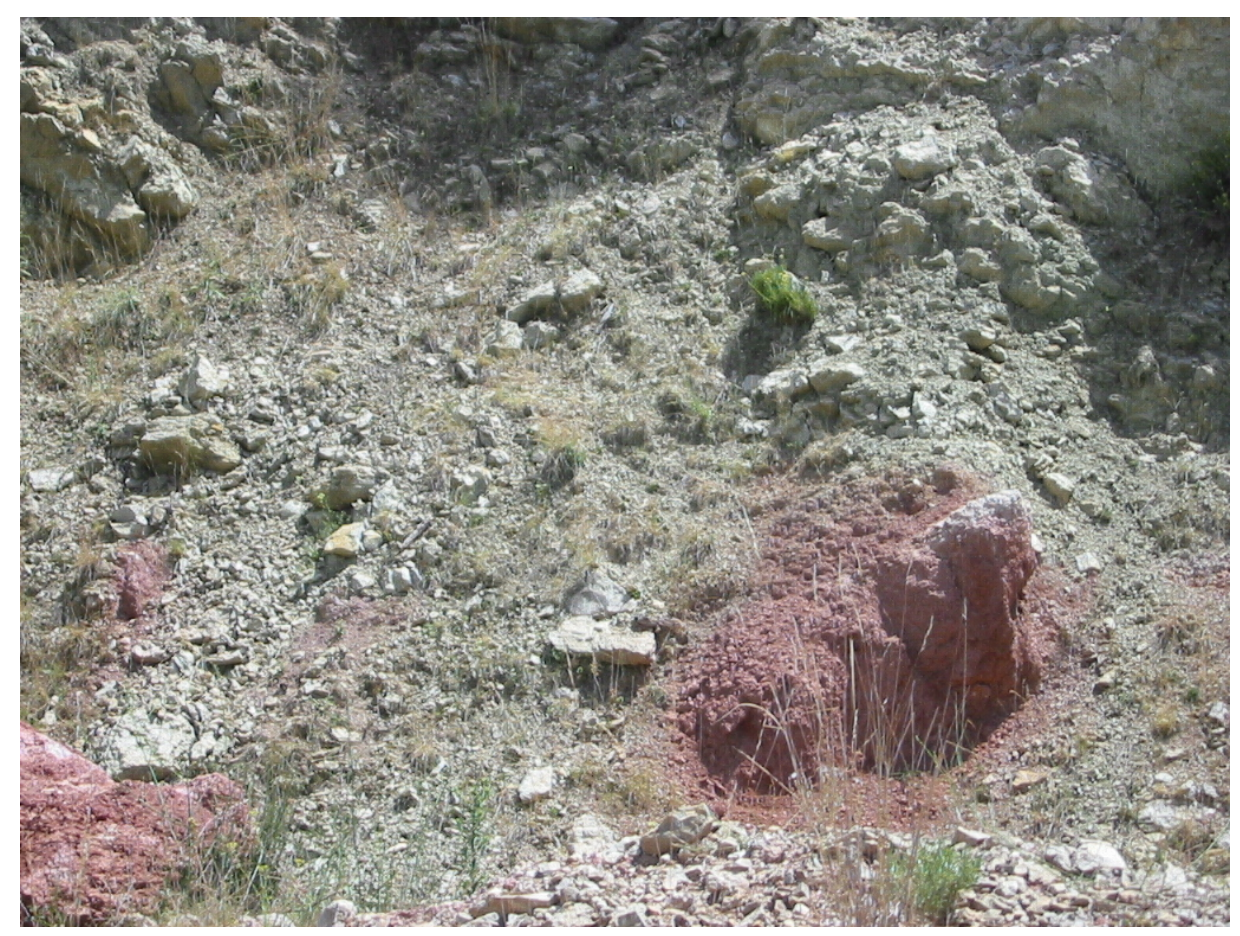

FOTOGRAFIA 3 (PARADA 3)

Bossades de rebliment kàrstic per bauxites, Calcaries del Juràssic

\section{PARADA 6 - CONDICIONAL. ERMITA DE SANT MIQUEL, (terme de Fondespatla, comarca del Matarranya). (Full 520).}

Des de la parada anterior, cal fer un breu recorregut, cap a Fondespatla. Abans, caldrà retornar a la carretera. En arribar al poble, cal anar cap a la propera ermita de Sant Miquel. Així, s'haurà efectuat un recorregut d'uns 5’5 Km.

En aquest recorregut, una vegada retornats a la carretera, s'han anat tallant els nivells oligocènics del Grup del Guadalope-Castellote, els quals es troben molt verticalitzats, tot forma part de la zona de l'Avant-país. Aquests materials són equivalents als de Gandesa-Horta de Sant Joan

En arribar a l'indret de l'aturada, es poden observar com apareix una inflexió en la vergència de les estructures de la Zona d'Enllaç, dons es passa d'una direcció ENE- 
OSO, a una altra ESE-ONO; és a dir durs arrumbaments de tipus catalans a d'altres ibèrics; tot i que en aquest indret no hi ha afloraments mesozoics, i les vergències afecten als materials terciaris, de l'Avant-país. Finalment, cal dir que aquestes estructures, constitueixen l'extrem oriental de la làmina d'encavalcament de Fondespatla - la Canyada de Beric - Alcorisa.

\section{EN AQUEST INDRET FINALITZA EL RECORREGUT}

\section{REFERÈNCIES BIBLIOGRÀFIQUES}

GUIMERÀ, J. et altri (1992).- Geologia (II), Història Natural dels Països Catalans, Vol.2, 547 pag. Enciclopèdia Catalana, S.A. Barcelona

IGME (1974).- Mapa Geológico de España a escala 1:200.000. Sintesis de la Cartografia existente. Hoja y memória nº 41 (Tortosa). Inst. Geol. Min. España. Minist. Indústria. Madrid

MATA-PERELLÓ, J.M. (1989).- Una recerca mineralògica per les terres de l’Ebre: del Matarranya al Priorat. But. Col. Ofi, de Doctors i Llicenciats, ${ }^{\circ}{ }^{67}$, 15pag. Barcelona

MATA-PERELLÓ, J.M. (1991).- Els Minerals de Catalunya. Arxius de la Secció de Ciències, t. XCIII, 442 pag. Institut d'Estudis Catalans. Barcelona

MATA-PERELLÓ, J.M. (1995a).- Inventari Mineralògic de la comarca de la Ribera d’Ebre, Terra Endins, nº 9, 23 pag. Manresa

MATA-PERELLÓ, J.M. (1995b).- Inventari Mineralògic de la comarca de la Terra Alta, Terra Endins, $\mathrm{n}^{\circ}$ 10, 22 pag. Manresa

MATA-PERELLÓ, J.M. (1996).- Itinerari geològic i mineralògic entre Gandesa, la Fontcalda i Vall-de -roures. Inèdit., 12 pàgines. Manresa

MATA-PERELLÓ. J.M. (1997).- Recerca geològica i mineralògica per les comarques de la Terra Alta i del Matarranya: des de Gandesa a Bot i Horta de Sant Joan, i des de Vallde-roures a Fondespatlla. Inèdit, 17 pàg. Manresa

MATA-PERELLÓ. J.M. (2000a).- Recerca geològica i mineralògica per les comarques de la Terra Alta i de la Ribera de l'Ebre: des de Pinell de Brai i Prat de Compte a Gandesa i a Mora d'Ebre. Algeps, sèrie B, no 171, 14 pàg. Manresa

MATA-PERELLÓ. J.M. (2000b).- Recerca geològica i mineralògica per les comarques de la Terra Alta i del Matarranya: des de Gandesa a Vall-de-roures i a Fondespatlla. Algeps, sèrie $B, \mathrm{n}^{0}$ 176, 18 pàg. Manresa 
MATA-PERELLÓ. J.M. (2001a).- Recorregut de recerca geològica i mineralògica per les comarques de la Ribera d'Ebre i de la Terra Alta: des d'Ascó a Pinell de Brai, i des de Prat de Compte a Horta de Sant Joan, Inèdit, 18 pàg. Manresa

MATA-PERELLÓ. J.M. (2001b).- Recorregut de recerca geològica i mineralògica per les comarques de la Terra Alta i del Matarranya: des d'Horta de Sant Joan a Vall-de-roures i a Fontespatlla Inèdit, 18 pàg. Manresa

MATA-PERELLÓ. J.M. (2005a).- Recorreguts per la comarca de la Terra Alta: des de Pinell de Brai a Prat de Compte i a Horta de Sant Joan. Inèdit. 12 pàgines. Manresa

MATA-PERELLÓ. J.M. (2005b).- Recorreguts de recerca geològica i mineralògica per les comarques de la Terra Alta i del Matarranya: des d'Arnes a Vall-de-roures i Beseit. Inèdit. 10 pàgines. Manresa

MATA-PERELLÓ. J.M. (2011).- Recorregut de recerca geològica i mineralògica per la comarca del Matarranya: des de Beseit a Fondespatla. Inèdit. 12 pàgines. Manresa

RIBA, O. et altri (1976).- Geografia Física dels Països Catalans, Edit. Ketres, 254 pàgines. Barcelona. 
RODENO. Revista de geología aragonesa 